University of Nebraska - Lincoln

DigitalCommons@University of Nebraska - Lincoln

USDA National Wildlife Research Center - Staff Publications
U.S. Department of Agriculture: Animal and Plant Health Inspection Service

2012

\title{
Bioeconomic Modelling of Raccoon Rabies Spread Management Impacts in Quebec, Canada
}

\author{
S. A.. Shwiff \\ USDA/APHIS/WS National Wildlife Research Center, stephanie.a.shwiff@aphis.usda.gov \\ C. Aenishaenslin \\ Universite de Montreal
}

A. Ludwig

Agence de la santé publique du Canada

P. Berthiaume

Agence de la santé publique du Canada

M. Bigras-Poulin

Universite de Montreal

See next page for additional authors

Follow this and additional works at: https://digitalcommons.unl.edu/icwdm_usdanwrc

Shwiff, S. A..; Aenishaenslin, C.; Ludwig, A.; Berthiaume, P.; Bigras-Poulin, M.; Kirkpatrick, K.; Lambert, L.; and Bélanger, D., "Bioeconomic Modelling of Raccoon Rabies Spread Management Impacts in Quebec, Canada" (2012). USDA National Wildlife Research Center - Staff Publications. 1086.

https://digitalcommons.unl.edu/icwdm_usdanwrc/1086

This Article is brought to you for free and open access by the U.S. Department of Agriculture: Animal and Plant Health Inspection Service at DigitalCommons@University of Nebraska - Lincoln. It has been accepted for inclusion in USDA National Wildlife Research Center - Staff Publications by an authorized administrator of DigitalCommons@University of Nebraska - Lincoln. 


\section{Authors}

S. A.. Shwiff, C. Aenishaenslin, A. Ludwig, P. Berthiaume, M. Bigras-Poulin, K. Kirkpatrick, L. Lambert, and D. Bélanger 
The major economic impacts of raccoon rabies are derived from human post-exposure prophylaxis (PEP), animal rabies tests (AT), human exposure investigations (INVT), livestock deaths, pet vaccinations and public education efforts (Meltzer and Rupprecht, 1998a,b; Sterner and Sun, 2004). Recent economic assessments have shown that these economic impacts spike during rabies epizootics, and have attempted to quantify both rabiesand ORV-incurred costs (Uhaa et al., 1992; Kreindel et al., 1998; Chang et al., 2002; Foroutan et al., 2002; Nunan et al., 2002; Shwiff et al., 2007, 2009, 2011). Additional economic analyses have evaluated ORV programmes using benefit-cost analysis (BCA), with increased PEP, AT and pet vaccinations as the principle driver of cost (Meltzer, 1996; Kemere et al., 2002; Shwiff et al., 2008).

Raccoon rabies was first detected in southern Quebec along the US (Vermont) border in 2006. Previously, the province had been considered raccoon rabies free and it is assumed that the disease was introduced via wildlife movement across the international boundary. The number of detected raccoon rabies-positive animal cases increased from four in 2006 to 66 in 2007 and 32 in 2008. Because of the close proximity of human and raccoon populations in Quebec, the wide range (including urban) and density of raccoon populations and continued priority given to raccoon rabies control within the United States, the Quebec government initiated a raccoon rabies control programme. Between 2006 and 2009, several million rabies vaccines targeting raccoons were distributed by air or ground over a 9500 square kilometre area of southern Quebec province to control this outbreak. This raccoon rabies control programme slowed the spread of the disease on the east side of the Richelieu River, $40 \mathrm{~km}$ southeast of Montreal city. Only two new cases of raccoon rabies in skunks were detected in the southern part of the infected area in 2009. Quebec effectively halted the spread and reduced the size of the epizootic through the province, thereby neutralizing the potential economic impacts associated with the spread of the disease.

This study provides an innovative bioeconomic methodology to estimate the benefits and costs associated with the Quebec raccoon rabies control programme starting in 2006 and projected until 2018. To estimate the potential benefits of the control programme, the methodology combines a dynamic spatial disease spread model for the simulation of the rabies epizootic among the raccoon population and economic quantification of the associated PEP, AT and INVT frequencies (Rees et al., 2009).

\section{Materials and Methods}

Benefit-cost analysis is a common tool used by economists to evaluate, among many others, government programmes and to determine the efficiency of management efforts. In a BCA, the monetary benefits and costs of programme actions are identified and compared (Nas, 1996). Estimating the economic benefit of preventing the spread of a previously undocumented variant of rabies into the province of Quebec, and potentially the rest of Canada, requires the quantification of non-marketed goods and services. One accepted methodology to value non-market services is the damage-avoided method, which uses the value of resources protected as a measure of the benefits provided by the raccoon rabies control programme. Here, it was posited that the raccoon rabies control programme slowed the movement of raccoon rabies into the study area. The benefits of the control programme were calculated as the savings from reducing the number of PEP, AT and INVT necessary, plus the associated costs that would potentially be borne by individuals as a result of human rabies exposure (e.g. expenditures on over-the-counter medications, lost work time and travel to receive treatment). These avoided costs make up the majority of benefits derived from rabies control programmes (Shwiff et al., 2008, 2009, 2011).

The raccoon rabies control programme began in 2006 and costs included salaries, vaccines, baits, aircraft operations, enhanced surveillance and public communication costs. Actual costs were used from 2006 to 2009 and then extrapolated into the future (up to 2018) based on 2009 levels, as this was the first year of full programme funding. Thus, for this study, total benefits and total costs of the raccoon rabies control programme were estimated from 2007 to 2018. The 12-year study period ending in 2018 used to evaluate the programme was based on practical considerations associated with government agencies ability to project the scale and scope of rabies control activities into the future.

\section{Disease spread modelling}

Because benefits are derived from the human population at risk (HPR), the objective of the disease spread simulation in a resident raccoon population was to calculate HPR located in and close to the areas infected by rabid raccoons. The model used was the Ontario Rabies Model (ORM; Rees et al., 2009). The ORM has been validated using genetic data (Rees, 2008; Rees et al., 2008a). Additional information on the ORM behaviour, including sensitivity analysis, is provided in Rees et al. (2008b).

The ORM is an individual-based stochastic and dynamic model using raccoons as simulated objects and has the ability to model the dispersion of raccoon rabies in a raccoon population through time and space. The study region was $32400 \mathrm{~km}^{2}$ and was located in southern Quebec province, delineated to the south by the border 
with the United States, to the North by the Saint Lawrence River and the southwest edge of the city of Quebec.

The first raccoon rabies case detected on 6 June 2006 by the passive public health surveillance system in Quebec was used as the index case of two simulated epizootic scenarios; one with control and one without control measures, spanning from 2006 to 2018. The simulated rabies control programmes were located in areas corresponding to the actual vaccination area (2006-2008). The control measures were only an approximation of the real control measures undertaken. For example, population reduction implemented in 2006 and 2007 was not taken into account, and the size of the ORV zone was not adjusted in relation to the geographic spread of raccoon rabies overtime. Hence, these simulations should not be interpreted as an evaluation of the field control programme. No cost reductions in the control programme were specifically simulated; however, the economic analysis incorporated certain efficiency gains associated with future projected baiting scenarios. Tinline, 2007 describes the selection procedure for the representative dispersion area to calculate the HPR, which was calculated using the 2006 population census data (Ludwig et al., 2009a). The HPR calculation follows the criteria proposed by the Institut national de santé publique du Québec (Lambert et al., 2007). The front of the simulated epizootic without control measures (baseline) reached the fringe of the defined study area as soon as 2011, while the simulated epizootics including control measures will not reach the border of the study area in 2018. To extend the baseline population at risk to 2018, the HPR for the epizootic without control measure was extrapolated from 2012 to 2018 based on the 2011 level. Therefore, no population increases or decreases are built into the model for the future (2012-2018) period in the specific case without control measures. Because raccoon rabies spreading North meant that rabies would impact the urban area of Montreal, it was realistic to assume this would be considered a risk for many years into the future by the responsible rabies management and public health agencies. The difference between the baseline HPR without control and the estimated HPR with control was those individuals that were not at risk of raccoon rabies exposure because of the control programme (Fig. 1). This difference between the two simulations represents the number of individuals protected by the programme and was used to calculate the benefits of the raccoon rabies control programme.

\section{Derivation of benefits}

The number of individuals protected or 'saved' by the programme was then combined with the rates of incidence of PEP, AT and INVT per 100000 people to

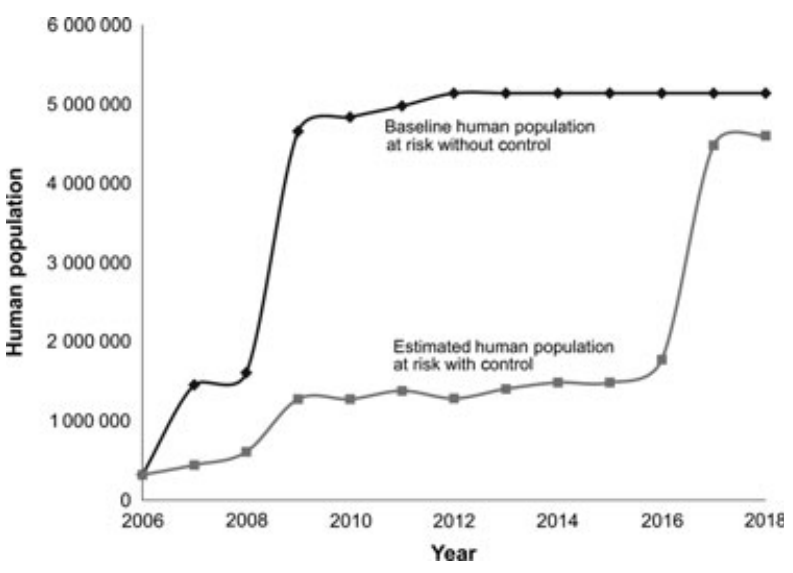

Fig. 1. Annual human population estimated to be at risk for rabies exposure (2006-2018).

monetize the benefits of the programme. To accomplish this, the annual case frequency of PEP and AT during raccoon rabies epizootics in the Eastern United States and Eastern Canada was used as proxies (Shwiff et al., 2008). Data regarding annual PEP and AT rates reported in New Jersey (Uhaa et al., 1992), New York (Wyatt et al., 1999) and New Brunswick (Department of Health, New Brunswick Provincial Government 2008, unpublished data) were used to determine the hypothetical case frequency that could have existed in the absence of a raccoon rabies control programme. New Jersey, New York and New Brunswick raccoon rabies epizootic PEP rates were reported as 66, 43.5 and 14; AT rates were reported as 483, 65 and 45 per 100000 people, respectively. Determination of the number of INVT was accomplished using data provided by the Direction de santé publique de l'Agence de la santé et des services sociaux de la Montérégie. Data collected in Montérégie, Quebec, from 1995 to 2006 (excluding bat exposure) indicate that for every PEP administered an average 8.71 (range, 4.07-20.17) INVT occurred. Therefore, in this report, the number of INVT was directly estimated based upon the PEP savings.

The annual total benefits equal PEP, AT and INVT costs owing to raccoon rabies cases saved. The predicted frequency level of PEPs per 100000 saved was the average number of PEPs per 100000 minus the actual number (the average number of PEPs from 1995 to 2006 reported in the study area). PEPs previous to 2006 raccoon variant rabies epizootic were the result of contact with different species of animals (excluding bat exposures). This information was combined with the costs associated with PEP annually. Two different levels of PEP costs were used for the analysis. For level 1, no indirect costs were included, and for level 2, the cost of PEP was increased by $33 \%$ to 
include indirect costs associated with rabies exposure. Shwiff et al. (2007) provides the most current and detailed estimation of direct and indirect costs associated with a rabid animal exposure. Direct costs refer to the vaccine, other biological materials and the health professional salaries, while indirect costs refer to over-the-counter medicines, travel to physicians and lost time from work associated with human rabies exposure. Indirect costs composed approximately one-third $(33 \%)$ of the total costs associated with a rabid animal exposure. The calculation of the cost savings related to AT was similar. The predicted frequency level of AT was compared to the actual number of ATs (the average number from 1995 to 2006 reported in the study area). This information was combined with the human population saved and the costs associated with AT, to calculate the cost savings during a particular year. The number of INVT was derived from the number of PEPs. This information was combined with the costs associated with INVT, to calculate the cost savings during a particular year.

The monetary savings per PEP, AT and INVT avoided were determined given the calculated number of cases prevented multiplied by the cost. The cost information for PEP, AT and INVT was estimated at $\$ 1463.75$ (rabies vaccines: $\$ 860$ for five doses, immunoglobulin: $\$ 516$ for a mean of $8 \mathrm{ml}$, salary of a nurse: $\$ 45 / \mathrm{h}$, mean duration of PEP administration: $1.5 \mathrm{~h}$. Costs and duration were provided by the Ministère de la santé et des services sociaux du Québec), \$269 (sample collection: \$172, sample shipping: $\$ 5$, travel: $\$ 40.60$, laboratory processing: $\$ 30$, quarantine of domestic animals: \$20, indemnification payment: $\$ 2.30 \$$. Costs were provided by Canadian Food Inspection Agency) and $\$ 124$ (mean salary of a health professional: $\$ 55 / \mathrm{h}$, mean duration of an investigation: $2.25 \mathrm{~h}$. Costs and duration were provided by the Ministère de la santé et des services sociaux du Québec) in 2008 Canadian dollars (CAD) per incident, respectively.

Estimation of these cost saving components permits the determination of the total programme benefits. The calculation of benefits was over the entire time period since the initiation of the control programme. All estimates of cost savings were calculated in 2008 dollars. Therefore, the total benefits calculated represent the present value of the entire raccoon rabies control programme for each year, from 2006 to 2018. It should be noted that not all benefits created by controlling raccoon rabies could be captured in this analysis. For example, the savings associated with a reduction in companion animal and livestock vaccinations along with any treatment (e.g. emergency care, quarantine, medications) were not factored into the analysis because of data limitations. Omission of these benefits creates more conservative programme benefit-cost ratios (Kemere et al., 2002).

\section{Derivation of costs}

Three control programme cost scenarios were developed to model future costs (Table 1). Scenario 1 does not include any future cost reductions; however, in Scenarios 2 and 3, the potential for future efficiency gains in the raccoon rabies control programme was modelled as reductions in future costs. For example, future efficiency gains could be produced by new ORV baits with higher efficacy potentially reducing the number of baits distributed on the landscape leading to an overall reduction in costs. The parameter values of the disease spread model were not modified to reflect possible impact of the choice of any of the three cost scenarios. This analysis determined the overall impact of reduced budgetary expenditures on the breakeven year and on programme efficiency. Contingency actions costs or costs associated with a disruption (e.g. flare-up of rabies in a previously controlled area) in the control programme were not included in this analysis. Contingency actions are not always necessary for programme success, and future analysis could include an examination of the impact of contingency actions.

\section{Results}

Total benefits accruing to the raccoon rabies control programme were the calculated savings owing to the programme (the projected prevented number of PEPs, ATs and INVTs and their cost to society) over the study period 2007-2018 (Tables 2 and 3). When the estimated benefits were compared to the costs of the raccoon rabies control programme, the potential ratios of benefits to

Table 1. Estimated Quebec raccoon rabies control programme cost projections for scenarios 1, 2, and 3 (costs maintained versus future efficiency gains)*

\begin{tabular}{llll}
\hline Year & Scenario 1 & Scenario 2 & Scenario 3 \\
\hline 2006 & $\$ 1383008$ & $\$ 1383008$ & $\$ 1383008$ \\
2007 & $\$ 4474350$ & $\$ 4474350$ & $\$ 4474350$ \\
2008 & $\$ 4452600$ & $\$ 4452600$ & $\$ 4452600$ \\
2009 & $\$ 3833000$ & $\$ 3833000$ & $\$ 3833000$ \\
2010 & $\$ 3833000$ & $\$ 3833000$ & $\$ 383000$ \\
2011 & $\$ 3833000$ & $\$ 3833000$ & $\$ 2299800$ \\
2012 & $\$ 3833000$ & $\$ 3833000$ & $\$ 2299800$ \\
2013 & $\$ 3833000$ & $\$ 1916500$ & $\$ 2299800$ \\
2014 & $\$ 3833000$ & $\$ 1916500$ & $\$ 2299800$ \\
2015 & $\$ 3833000$ & $\$ 1916500$ & $\$ 1533200$ \\
2016 & $\$ 3833000$ & $\$ 1916500$ & $\$ 1533200$ \\
2017 & $\$ 3833000$ & $\$ 1916500$ & $\$ 1533200$ \\
2018 & $\$ 3833000$ & $\$ 1916500$ & $\$ 1533200$ \\
Total & $\$ 48639958$ & $\$ 37140958$ & $\$ 33307958$ \\
\hline
\end{tabular}

*All numbers in 2008 CAD. 
Table 2. Estimated level 1 number and value of prevented raccoon rabies impacts: post-exposure prophylaxis (PEP), animal testing (AT) and human exposure investigation (INVT) from 2007 to 2018*

\begin{tabular}{llllllll}
\hline Year & PEP & PEP Savings & AT & AT Savings & INVT & INVT Savings & Total/year \\
\hline 2007 & 396 & $\$ 579849$ & 1736 & $\$ 467057$ & 3450 & $\$ 428925$ & $\$ 1475831$ \\
2008 & 391 & $\$ 572243$ & 1713 & $\$ 460930$ & 3405 & $\$ 423298$ & $\$ 1456471$ \\
2009 & 1324 & $\$ 1938500$ & 5805 & $\$ 1561423$ & 11535 & $\$ 1439943$ & $\$ 4933866$ \\
2010 & 1394 & $\$ 2041066$ & 6112 & $\$ 1644038$ & 12145 & $\$ 1509813$ & $\$ 5194917$ \\
2011 & 1409 & $\$ 2062762$ & 6177 & $\$ 1661514$ & 12274 & $\$ 1525862$ & $\$ 5250137$ \\
2012 & 1510 & $\$ 210332$ & 6619 & $\$ 1780378$ & 13153 & $\$ 1635022$ & $\$ 5625733$ \\
2013 & 1463 & $\$ 2141310$ & 6412 & $\$ 1724782$ & 12742 & $\$ 1583965$ & $\$ 5450056$ \\
2014 & 1431 & $\$ 2095332$ & 6274 & $\$ 1687748$ & 12468 & $\$ 1549954$ & $\$ 5333034$ \\
2015 & 1431 & $\$ 2095332$ & 6274 & $\$ 1687748$ & 12468 & $\$ 1549954$ & $\$ 5333034$ \\
2016 & 1318 & $\$ 1929590$ & 5778 & $\$ 1554246$ & 11482 & $\$ 1427352$ & $\$ 4911189$ \\
2017 & 257 & $\$ 376431$ & 1127 & $\$ 303208$ & 2240 & $\$ 278453$ & $\$ 958092$ \\
2018 & 210 & $\$ 307742$ & 921 & $\$ 247880$ & 1831 & $\$ 227642$ & $\$ 783265$ \\
Total & 12537 & $\$ 18350490$ & 54948 & $\$ 14780952$ & 109194 & $\$ 13574183$ & $\$ 46705625$ \\
\hline
\end{tabular}

*All numbers in 2008 CAD.

Table 3. Estimated level 2 number and value of prevented raccoon rabies impacts: prevented post-exposure prophylaxis (PEP), animal testing (AT) and human exposure investigation (INVT) from 2007 to 2018 *

\begin{tabular}{llllllll}
\hline Year & PEP & PEP Savings & AT & AT Savings & INVT & INVT Savings & Total/year \\
\hline 2007 & 396 & $\$ 771199$ & 1736 & $\$ 467057$ & 3450 & $\$ 428925$ & $\$ 1672764$ \\
2008 & 391 & $\$ 761083$ & 1713 & $\$ 460930$ & 3405 & $\$ 423298$ & $\$ 1650820$ \\
2009 & 1324 & $\$ 2578205$ & 5805 & $\$ 1561423$ & 11535 & $\$ 1439943$ & $\$ 5592235$ \\
2010 & 1394 & $\$ 2714618$ & 6112 & $\$ 1644038$ & 12145 & $\$ 1509813$ & $\$ 5888120$ \\
2011 & 1409 & $\$ 2743474$ & 6177 & $\$ 1661514$ & 12274 & $\$ 1525862$ & $\$ 5950709$ \\
2012 & 1510 & $\$ 2939742$ & 6619 & $\$ 1780378$ & 13153 & $\$ 1635022$ & $\$ 6376424$ \\
2013 & 1463 & $\$ 2847942$ & 6412 & $\$ 1724782$ & 12742 & $\$ 1583965$ & $\$ 6177305$ \\
2014 & 1431 & $\$ 2786792$ & 6274 & $\$ 1687748$ & 12468 & $\$ 1549954$ & $\$ 6044668$ \\
2015 & 1431 & $\$ 2786792$ & 6274 & $\$ 1687748$ & 12468 & $\$ 1549954$ & $\$ 6044668$ \\
2016 & 1318 & $\$ 2566355$ & 5778 & $\$ 1554246$ & 11482 & $\$ 1427352$ & $\$ 5566532$ \\
2017 & 257 & $\$ 500654$ & 1127 & $\$ 303208$ & 2240 & $\$ 278453$ & $\$ 1085939$ \\
2018 & 210 & $\$ 409297$ & 921 & $\$ 247880$ & 1831 & $\$ 227642$ & $\$ 887783$ \\
Total & 12537 & $\$ 24406152$ & 54948 & $\$ 14780952$ & 109194 & $\$ 13574183$ & $\$ 52937965$ \\
\hline
\end{tabular}

*All numbers in 2008 CAD.

costs were determined. In this analysis, total (cumulative) programmatic benefit-cost ratios ranged from 0.96 to 1.55 (Tables 4 and 5). This indicates every dollar spent on the raccoon rabies control programme saves between $\$ .96$ and $\$ 1.55$ in prevented costs to society.

\section{Level 1}

This level of benefits omitted any savings derived from indirect costs associated with PEP (Table 2). Future reductions in programme costs matter in terms of overall programme economic efficiency. Under scenario 1, the overall programme benefits are approximately equal to costs with a ratio of benefits to costs of .98 , mainly owing to the static nature of long-term programme costs. For scenarios 2 and 3, overall benefits exceed the costs when estimated over the life of the programme.

\section{Level 2}

Inclusion of the indirect cost savings associated with PEP more accurately reflects the cost burden associated with human exposure to rabies (Table 3). Under all costs scenarios, overall programme benefits exceed costs. The combination of indirect costs associated with PEP and long-term programme cost savings provides the best potential returns associated with the programme, with benefits ( $\$ 6044668$ ) approximately four times greater than costs (\$1533 200).

\section{Discussion}

Successful elimination of the spread of an expensive and deadly disease like raccoon variant rabies often leaves economists, public health organizations and legislators 
Table 4. Estimated benefit-cost ratios for level 1 benefits (PEP direct cost savings only) and three calculated cost scenarios (costs maintained versus future efficiency gains), from 2007 to 2018

\begin{tabular}{|c|c|c|c|c|c|c|}
\hline \multirow[b]{2}{*}{ Year } & \multicolumn{2}{|c|}{ Scenario 1} & \multicolumn{2}{|c|}{ Scenario 2} & \multicolumn{2}{|c|}{ Scenario 3} \\
\hline & $B C R$ & BCR/year & $\mathrm{BCR}$ & $\mathrm{BCR} /$ year & $B C R$ & BCR/year \\
\hline 2007 & 0.03 & 0.33 & 0.04 & 0.33 & 0.04 & 0.33 \\
\hline 2008 & 0.06 & 0.33 & 0.08 & 0.33 & 0.09 & 0.33 \\
\hline 2009 & 0.16 & 1.29 & 0.21 & 1.29 & 0.24 & 1.29 \\
\hline 2010 & 0.27 & 1.36 & 0.35 & 1.36 & 0.39 & 1.36 \\
\hline 2011 & 0.38 & 1.37 & 0.49 & 1.37 & 0.55 & 2.28 \\
\hline 2012 & 0.49 & 1.47 & 0.64 & 1.47 & 0.72 & 2.45 \\
\hline 2013 & 0.60 & 1.42 & 0.79 & 2.84 & 0.88 & 2.37 \\
\hline 2014 & 0.71 & 1.39 & 0.93 & 2.78 & 1.04 & 2.32 \\
\hline 2015 & 0.82 & 1.39 & 1.08 & 2.78 & 1.20 & 3.48 \\
\hline 2016 & 0.92 & 1.28 & 1.21 & 2.56 & 1.35 & 3.20 \\
\hline 2017 & 0.94 & 0.25 & 1.24 & 0.50 & 1.38 & 0.62 \\
\hline 2018 & 0.96 & 0.20 & 1.26 & 0.41 & 1.40 & 0.51 \\
\hline
\end{tabular}

Table 5. Estimated benefit-cost ratios for level 2 benefits (post-exposure prophylaxis indirect cost savings included) and three calculated cost scenarios (costs maintained versus future efficiency gains), from 2007 to 2018

\begin{tabular}{|c|c|c|c|c|c|c|}
\hline \multirow[b]{2}{*}{ Year } & \multicolumn{2}{|c|}{ Scenario 1} & \multicolumn{2}{|c|}{ Scenario 2} & \multicolumn{2}{|c|}{ Scenario 3} \\
\hline & $\mathrm{BCR}$ & BCR/year & $\mathrm{BCR}$ & $\mathrm{BCR} /$ year & $B C R$ & BCR/year \\
\hline 2007 & 0.03 & 0.37 & 0.04 & 0.37 & 0.05 & 0.37 \\
\hline 2008 & 0.07 & 0.37 & 0.09 & 0.37 & 0.10 & 0.37 \\
\hline 2009 & 0.18 & 1.45 & 0.24 & 1.45 & 0.27 & 1.45 \\
\hline 2010 & 0.30 & 1.53 & 0.40 & 1.53 & 0.44 & 1.53 \\
\hline 2011 & 0.43 & 1.55 & 0.56 & 1.55 & 0.62 & 2.58 \\
\hline 2012 & 0.56 & 1.66 & 0.73 & 1.66 & 0.81 & 2.76 \\
\hline 2013 & 0.68 & 1.61 & 0.89 & 3.21 & 1.00 & 2.68 \\
\hline 2014 & 0.81 & 1.57 & 1.06 & 3.14 & 1.18 & 2.62 \\
\hline 2015 & 0.93 & 1.57 & 1.22 & 3.14 & 1.36 & 3.93 \\
\hline 2016 & 1.04 & 1.45 & 1.37 & 2.89 & 1.52 & 3.62 \\
\hline 2017 & 1.07 & 0.28 & 1.40 & 0.56 & 1.56 & 0.71 \\
\hline 2018 & 1.08 & 0.23 & 1.42 & 0.46 & 1.58 & 0.58 \\
\hline
\end{tabular}

wondering what would have been the monetary consequences if the programme had not been successful. This study provided a methodology to estimate the economic impact of limiting the spread of rabies, when compared with classically used methods. One main difficulty in bioeconomic modelling of most zoonotic diseases lies in the accurate prediction of HPR. Previously reported methodologies for the calculation of the HPR for rabies either consider the entire study area at risk once the first case has been detected (Uhaa et al., 1992; Aubert, 1999) or consider that only a restricted part of the study area is at risk at the detection of the first case and then expand through the area based on arbitrary choices (Shwiff et al., 2009) or according to the expansion of the epizootic front at constant speed (Kemere et al., 2002; Shwiff et al., 2008). The most significant contribution of this study includes adding additional sophistication to the economic analysis by enhancing the quantification of HPR based upon the simulation of disease spread within the raccoon population. The use of this mathematical model made it possible to include many biological aspects neglected by more conventional approaches (i.e. biology of the disease vector, such as birth rate, mortality rates, movements) and produce estimates of disease spread more specific to the conditions in the study area. This study shows preventing the entry of the disease into a highly populated urban area such as Montreal is crucial to achieve cost efficiency in a rabies control programme and should be prioritized as an objective of the programme. For these reasons, we believe this study illustrates a useful tool for decision-making.

Another challenge of this study was determining the hypothetical annual frequencies of public health interventions (PEP, AT and INVT) that would have existed in the absence of a raccoon rabies control programme, which were used to calculate damages avoided in the economic analysis. The estimated frequencies were based on information from the raccoon rabies epizootics in New Brunswick, New Jersey and New York. The use of these average and adjusted frequencies reduces uncertainty of the monetary value of damages avoided; however, inclusion of additional information would further refine the results, thus underlining the need for more reported and published data on the effects of rabies epizootics on public health interventions. A range of potential programme benefits (levels 1 and 2) were estimated to compare with three programmatic control cost scenarios. This prospective analysis of the control programme to prevent the spread and eventual elimination of the emerging raccoon rabies in the province of Quebec indicated economic efficiency of the programme for a variety of modelled outcomes. Some modelled outcomes indicated that efficiency is not possible given the derived benefits and the estimated costs signalling a potentially inefficient use of government expenditures.

This analysis estimated a range of potential future control programme costs. A static budget into the future, while potentially realistic, does not convey the possibility of reduced control programme expenditures owing to either efficiency gains within the programme or containment or elimination of the raccoon rabies variant in the province. For example, in Texas, an initial ORV programme contained the spread of the domestic dog coyote-variant rabies and an ORV zone was established at the United States - Mexico border to prevent the reintroduction into Texas (Sidwa et al., 2005). Costs associated with containing the spread of the variant in Texas were higher than the subsequent years when costs were only 
related to maintaining the ORV zone (Shwiff et al., 2008). It is possible that similar efficiency gains through economies of scale in the baiting programme or potential increases in vaccine efficiency could also be realized with the control programme. Following the completion of the study, the inclusion of future programme efficiency gains with the BCA has been supported. In Quebec, despite the diminishing budget for rabies control and the size of the baited area remaining consistent, the efficiency of baiting techniques has been ameliorated.

In conclusion, economic efficiency is one of the many factors that play a role in determining the utility of rabies control programmes. This study provides an example of how to estimate the cost efficiency of a raccoon rabies control programme, even though many unknowns were involved in the original decision. In this work, stochastic elements were only included to simulate disease spread. This analysis can be used as the foundation for several future analyses; first, the incorporation of stochasticity into the economic parameterizing of elements such PEP, AT and INVT, and second, the use of economic computer simulation software to model the change in economic activity as a result of the control of raccoon rabies. All bioeconomic modelling systems possess an inherent variability, and the inclusion of a more comprehensive set of stochastic components in the modelling process would provide for probability distributions of the bioeconomic outputs from the model instead of a limited, discrete set of scenario results (Ludwig et al., 2009b). Future research to model the economic impact of government spending to prevent the spread of raccoon rabies in Quebec could use the information provided in this analysis to inform economic impact input-output modelling software. This would certainly be of even greater interest for decisionmakers and stakeholders in the process of programme implementation or continuity evaluation.

\section{Acknowledgements}

Funding for this study was provided by the government of Quebec and the Public Health Agency of Canada.

\section{References}

Aubert, M. F. A., 1999: Costs and benefits of rabies control wildlife in France [in French]. Rev. Sci. Tech. 18, 533-543.

Blanton, J. D., K. Robertson, D. Palmer, and C. E. Rupprecht, 2009: Rabies surveillance in the United States during 2008.

J. Am. Vet. Med. Assoc. 235, 676-689.

Chang, H., M. Eidson, C. Noonan-Toly, C. V. Trimarchi, R. Rudd, B. J. Wallace, P. F. Smith, and D. L. Morse, 2002: Public health impact of re-emergence of rabies, New York. Emerg. Infect. Dis. 8, 909-913.
Foroutan, P., M. I. Meltzer, and K. A. Smith, 2002: Cost of distributing oral raccoon-variant rabies vaccine in Ohio: 1997-2000. J. Am. Vet. Med. Assoc. 220, 27-32.

Kemere, P., M. K. Liddel, P. Evangelou, D. Slate, and S. Osmek, 2002: Economic analysis of a large scale oral vaccination program to control raccoon rabies. In: Clark, L., J. Hone, J. A. Shivik, R. A. Watkins, K. C. Vercauteren and J. K. Yoder (eds), Human Conflicts with Wildife: Economic Considerations, pp. 109-116. United States Department of Agriculture, Animal and Plant Health Inspection Service, National Wildlife Research Center, Fort Collins, CO.

Kreindel, S. M., M. McGill, M. I. Meltzer, C. Rupprecht, and A. DeMaria Jr, 1998: The cost of rabies postexposure prophylaxis: one state's experience. Public Health Rep. 113, 247251.

Lambert, L., D. Deshaies, C. Gaulin, S. Lacoursière, and J. Picard, 2007: Guide d'intervention visant la prévention de la rage humaine [In French]. Comité sur la révision du protocole d'intervention visant la prévention de la rage humaine, Table de concertation nationale en maladies infectieuses, Ministère de la santé et des services sociaux du Québec. Available at: http://www.agencesssgim.ca/fichiers/agence/Sante_publique/Guide_d_intervention_rage_juin_2007.pdf (accessed October 21, 2008).

Ludwig, A., P. Berthiaume, S. Brazeau, M. Bigras-Poulin, and D. Bélanger, 2009a: Calculating the human population at risk for contracting raccoon rabies in southern Québec for use in a cost-benefit analysis [In French]. Technical Report, Groupe de recherche en épidémiologie des zoonoses et santé publique, Université de Montréal, Saint-Hyacinthe.

Ludwig, A., P. Berthiaume, S. Brazeau, and M. Bigras-Poulin, 2009b: Stochastic modeling to estimate the human population at risk in a cost-benefit analysis of raccoon rabies control programs, Rabies in the America, Québec (QC) Canada. MacInnes, C. D., S. M. Smith, R. R. Tinline, N. R. Ayers, P. Bachmann, D. G. A. Ball, L. A. Calder, S. J. Crosgrey, C. Fielding, P. Hauschildt, J. M. Honig, D. H. Johnston, K. F. Lawson, C. P. Nunan, M. A. Pedde, B. Pond, R. B. Stewart, and D. R. Voigt, 2001: Elimination of rabies from red foxes in Eastern Ontario. J. Wildl. Dis. 37, 119-132.

Meltzer, M. I., 1996: Assessing the costs and benefits of an oral vaccine for raccoon rabies: a possible model. Emerg. Infect. Dis. 2, 343-349.

Meltzer, M. I., and C. E. Rupprecht, 1998a: A review of the economics of the prevention and control of rabies, Part 1: global impact and rabies in humans. Pharmacoeconomics 14, 366-383.

Meltzer, M. I., and C. E. Rupprecht, 1998b: A review of the economics of the prevention and control of rabies, Part 2: rabies in dogs, livestock and wildlife. Pharmacoeconomics 14, 481-498.

Nas, T. F., 1996: Cost-Benefit Analysis: Theory and Application. Sage Publications, Inc., Thousand Oaks, CA. 
Niezgoda, M., C. A. Hanlon, and C. E. Rupprecht, 2002: Animal rabies. In: Jackson, A. C., and W. H. Wunner (eds), Rabies, pp. 201-258. Academic Press, San Diego, CA.

Nunan, C. P., R. R. Tinline, J. M. Honig, D. G. A. Ball, P. Hauschildt, and C. A. LeBer, 2002: Postexposure treatment and animal rabies, Ontario, 1958-2000. Emerg. Infect. Dis. 8, 217.

Rees, E. E. 2008: Approaches to modelling raccoon rabies, PhD thesis, Trent University, Canada.

Rees, E. E., B. A. Pond, C. I. Cullingham, R. R. Tinline, D. Ball, C. J. Kyle, and B. N. Wite, 2008a: Assessing a landscape barrier using genetic simulation modelling: implications for raccoon rabies management. Prev. Vet. Med. 86, 107-123.

Rees, E. E., B. A. Pond, J. R. Phillips, and D. Murray, 2008b: Raccoon ecology database: a resource for population dynamics modelling and meta-analysis. Ecol. Inform. 3, 87-96.

Rees, E. E., B. A. Pond, C. I. Cullingham, R. R. Tinline, D. Ball, J. K. Christopher, and B. N. White, 2009: Landscape modelling spatial bottlenecks: implications for raccoon rabies disease spread. Biol. Lett. 5, 387-390.

Shwiff, S. A., R. T. Sterner, M. Jay-Russell, S. Parikh, A. Bellomy, and M. I. Meltzer, 2007: Direct and indirect costs of rabies exposure: a retrospective study in Southern California (1998-2002). J. Wildl. Dis. 43, 251-257.

Shwiff, S. A., K. N. Kirkpatrick, and R. T. Sterner, 2008: Economic evaluation of an oral rabies vaccination program for control of a domestic dog-coyote rabies epizootic: 19952006. J. Am. Vet. Med. Assoc. 233, 1736-1741.

Shwiff, S. A., R. T. Sterner, R. Hale, M. Jay-Russell, B. Sun, and D. Slate, 2009: Benefit-cost scenarios of potential oral rabies vaccination for skunks in California. J. Wildl. Dis. 45, 227-233.

Shwiff, S. A., C. P. Nunan, K. N. Kirkpatrick, and S. S. Shwiff, 2011: A retrospective economic analysis of the ontario red fox oral rabies vaccination programme. Zoonoses Public Health 58, 169-177.

Sidwa, T. J., P. J. Wilson, G. M. Moore, E. H. Oertli, B. N. Hicks, R. E. Rohde, and D. H. Johnston, 2005: Evaluation of oral rabies vaccination programs for control of rabies epizootics in coyotes and gray foxes: 1995-2003. J. Am. Vet. Med. Assoc. 227, 785-792.

Sterner, R. T., and B. Sun, 2004: Relative factor costs of wildlife rabies impacts in the US. Proc. Vertebr. Pest Conf. 21, 185-189.

Tinline, R. R., 2007: The Ontario Rabies Model Guide. GIS Lab, Queen's University, Kingston, ON.

Uhaa, I. J., V. M. Data, F. E. Sorhage, J. W. Beckley, D. E. Roscoe, and R. D. Gorsky, 1992: Benefits and costs of using an orally absorbed vaccine to control rabies in raccoons. J. Am. Vet. Med. Assoc. 201, 1873-1882.

Wyatt, J. D., W. H. Barker, N. M. Bennett, and C. A. Hanlon, 1999: Human rabies postexposure prophylaxis during a raccoon rabies epizootic in New York, 1993 and 1994. Emerg. Infect. Dis. 5, 415-423. 